\title{
SENTIDO DE LO \\ POÉTICO EN LAS \\ MEMORIAS DE \\ PABLO NERUDA
}

Ciro E. Schmidt*

Pablo Neruda, poeta chileno y premio Nobel de Literatura, una de las figuras cumbres de la poética contemporánea, ha expresado su vivencia en innumerables obras, a través de las cuales nos ha mostrado su sentir humano unido a su sentir como poeta. Desde la sencilla poesía de Odas elementales, pasando por las expresiones amorosas de los 20 poemas de amor y una canción desesperada, hasta la majestuosidad de Residencia en la tierra y Canto general, así como muchas otras, nos ha mostrado un profundo sentido de lo poético, el que, sin embargo, nunca sistematizó en forma reflexiva directa.

La obra de Pablo Neruda es magnífica no sólo en cuanto a su profundidad sino también en cuanto a su extensión. En este trabajo sólo pretendo lograr algunas pautas de comprensión de su sentido de lo poético a partir de sus Memorias, que él mismo tituló Confieso que he vivido.

Desde este libro, que es una especie de autobiografia, aún cuando no en su sentido común, puede ordenarse algo de su propia expresión, especialmente en relación a las categorías que fundan su expresión como poeta.

* Instituto Profesional Santo Tomás, Puerto Montt, Chile. 
CIRO E. SCHMIDT

\section{Sentido de lo poético}

El arte surge en un intento de expresar la subjetividad más personal: el yo y sus opciones profundas, que comprometen la existencia y dirigen largos momentos, a veces la vida entera, opciones que cristalizan en maneras de ser. ${ }^{1}$ Lo propio del arte es revelar lo humano, pero de la misma manera que el hombre habla de lo humano en lo real después de haberlo humanizado son su praxis, el arte encuentra lo humano en esta iniciativa humana de transformación de la naturaleza.

La poesía, en sentido amplio, incluye todas las formas de arte en cuanto miradas desde lo humano, y se nos muestra orientada hacia algo, desde un determinado modo de percibirse el hombre a sí mismo y a la realidad que lo rodea. El poeta que cada uno es está 'ahí' en el momento en que actuamos y que intentamos buscar sentido, explicar y expresar simbólicamente. Jamás estamos más cerca de nuestras acciones y de las acciones de los demás que cuando las vivimos y expresamos poéticamente. ${ }^{2}$

La expresión poética es hacedora, creadora, fruto de un dinamismo interno que tiende a expresarse, por lo que tiene una íntima relación

124 con el lenguaje en todas sus formas.

El profeta y el poeta son hombres que han vivido o han intuido vivencias y que, entusiasmados, cuentan, por las palabras o las creaciones, las experiencias que han tenido, para que otros, a su vez, las vivan y las sigan viviendo. La capacidad poética se ejercita en el paso de la subjetividad de la vivencia a la objetividad de la palabra o del gesto, a la creación en todas sus formas. Por ello la acción surge como mediación hacia la 'dicción poética' en su sentido más ampiio. Es la emoción de extrañeza la que nos vincula más al mundo, a los otros y a nosotros mismos.

${ }^{1}$ Joseph De Finance, L'Affrontement de l'autre, 1973, Roma, Universitá Gregoriana Editrice, p. 115.

${ }^{2}$ José M. Arnaíz, Antropología del obrar humano, 1984, Santiago, Ediciones Paulinas, p. 329. 
Todo arte es la expresión lentamente conquistada del sentimiento fundamental que experimenta el artista frente a su mundo, y lo poético, por lo mismo, es lenguaje sugerente hecho a base de relaciones entre los sentimientos y ciertas objetividades.

El pensamiento vertido con las palabras en la poesía saca a luz la realidad tal como es experimentada en la intimidad del ánimo, de un modo que, mediante esta formulación verbal, lo que en la vivencia puede parecer oscuro se ilumine, aparezca como mostrable y se sitúe en el horizonte de la objetividad.

Millas nos indica que la experiencia poética se resuelve con la contemplación emocionalmente subjetivada, lo que implica que dice referencia, al mismo tiempo, a lo subjetivo y a lo objetivo como una forma nueva de relación entre ambos aspectos, en cuanto relación de la interioridad con el mundo que la rodea. La poesía ensancha el mundo subjetivo en cuanto encierra impactos emocionales del mundo en la conciencia y establece una relación emocional con las cosas, una conversión de su modo de ser propio y trascendente, en un modo de ser nuestro, subjetivo e inmanente. La significación afectiva constituye lo central de la estructura poética. ${ }^{3}$

La poesía redescubre las cosas penetrándolas hasta un fondo de sentidos insospechados. Mas estos sentidos poéticamente descubiertos no son determinaciones de las cosas qua cosas, nada de ellas mismas por consiguiente, sino determinaciones de nosotros ante ellas como fuentes de experiencia emocional. No es descripción de las cosas en su estructura objetiva sino revelación de sus inagotables posibilidades de resonancia en nosotros. ${ }^{4}$

Todo lo poético convierte lo universal en concreto. El poeta parte del contacto con la realidad por medio de la sensibilidad y la imaginación, $\mathrm{y}$ termina llevando un mensaje a hombres de una época y un lugar. ${ }^{5}$

${ }^{3}$ Jorge Millas, Idea de la Filosofia, 1970, Chile, Edit. Universitaria, t. I, p. 161-3, 165 .

${ }^{4}$ Ibid., p. 163.

${ }^{5}$ Ernst Cassirer, Antropología filosófica, 1965, México, FCE, p. 247. 
CIRO E. SCHMIDT

Allí la palabra es instauradora de lo que es y, por tanto, develadora de su verdad, por lo que el poeta es el custodio de la casa del Ser. E1 mundo de las cosas singulares, el de los nombres y las imágenes es el paraíso del poeta: allí se le da todo, lo próximo y lo lejano, lo actual y lo posible -con lo imposible- $y$, sobre todo, lo universal convertido en cosa existente, mas no en objeto sino en vivencia, en cosa hecha espejo de la subjetividad del alma. ${ }^{6}$

La palabra se da en el diálogo, el lugar de la palabra, que es la forma más propia de la comunicación, y el arte es comunicación o expresión de lo interior en su pretensión de hacer que la realidad hable en la palabra, en el impacto subjetivo. ${ }^{7}$ La palabra, al expresar lo real y hacerlo manifiesto, lo enmascara ocultándolo; lo esencial de lo poético estaría en el ritmo íntimo del lenguaje y en sus connotaciones metafóricas, y por lo mismo puede decirse que todo el arte en el fondo es poesía. "El poeta, en su obra, revela las dimensiones del vivir que en el mirar no poético no se ven, pero que él o ella hacen visibles a una mirada que acepta al mirar del poeta como válido." $\mathrm{Su}$ obra, por lo mismo, son voces que hacen presente la realidad en su espera y profundidad; de allí que la esencia de lo poético sea la metáfora.

126 Heidegger nos señala que "el lenguaje es la casa del ser, en el que el hombre ha establecido su morada", y hace especial referencia al lenguaje poético, mientras Gabriel Marcel nos indica que "nosotros estamos aquí en la raíz común de una cierta magia y de toda la poesía", y que "si volvemos ahora al problema de la designación (...) descubrimos que ella no puede ser realmente comprendida en un sentido suprafuncional sino como un acto de amor."10

${ }^{6}$ Millas, op cit., p. 177.

${ }^{7}$ Joaquín Barceló, "La Palabra y su función expresiva", 1972, Dilema, $\mathrm{n}^{\circ}$ $7-8$, p. 15.

${ }^{8}$ Sergio Peña Lillo, "Locura y poesía", El Mercurio, 23 de junio de 1966.

${ }^{9}$ Humberto Maturana, El sentido de lo humano, 1992, 2a., Santiago, Edit. Univ.

${ }^{10}$ Gabriel Marcel, El hombre problemático, p. 54. 
La poesía, como el arte, 'es visión simpática de las cosas', por ello necesitamos del sentido poético de la existencia para no perder nuestra identidad de criaturas únicas e irreemplazables, para no hundirnos en la barbarie automatizada. Por lo mismo, cabe preguntarse si puede tener cabida la sensibilidad y la poesía en medio de los fríos e implacables cánones del marketing, la economía de mercado, la computación y el consumismo ${ }^{11}$ Neruda nos muestra que más allá de las dificultades sí es posible, y que el hombre hoy anhela formas de vivir poético aun cuando no siempre este anhelo se haga conciencia.

Camus, comentando a Proust, señala que "no es que la naturaleza imite al arte. Es que el gran artista nos enseña a ver en la naturaleza lo que su obra ha sabido aislar en forma irremplazable". 12 Por lo mismo, el poeta es capaz de ir abriéndose a distintas visiones de sentido de lo poético en el crecer de su vivir. Las Memorias de Pablo Neruda nos muestran este crecer vitalmente poético.

\section{Desde Neruda y sus Memorias}

Las reflexiones anteriores no pretendían ser un tratado de lo poético sino darnos alguna forma de base paradigmática para reflexionar en torno a lo poético desde esta obra de Neruda, revisando algunas de sus propias expresiones en torno al quehacer de su expresión.

Este decir, que es más sentimiento que teoría, tiene raíces en su propia experiencia no sólo poética en sentido estricto sino vital, puesto que todo su vivir es poético y está empapado de una determinada forma de sentir.

Aun cuando no es tema de esta reflexión, puede servirnos de punto de partida una de sus odas, que de forma especial expresa este sentido 'simpático' entre la realidad de los hombres y la naturaleza. La ‘Oda al hombre invisible' con la que comienza sus Odas elementales es un

${ }^{11}$ Manuel Silva Acevedo, "Para una poética de la fe", El Mercurio, 5 de mayo de 1966.

${ }^{12}$ Albert Camus, Carnets, II, p. 184. 
CIRO E. SCHMIDT

canto manifestativo de su sentir poético, por lo mismo quiero citar algunos de sus versos para invitar a una reflexión en torno a su poesía.

todo vive

todos pasan,

y yo apenas tengo tiempo

para vestirme,

yo tengo que correr:

ninguno puede

pasar sin que yo sepa

adónde va, qué cosa

le ha sucedido

No puedo

sin la vida vivir,

sin el hombre ser hombre

y corro y veo y oigo

y canto...

Dadme para mi vida todas las vidas, dadme todo el dolor de todo el mundo, yo voy a transformarlo en esperanza...

dadme la lucha de cada día porque ellas son mi canto, y así andaremos juntos, codo a codo, todos los hombres, mi canto los reúne:

el canto del hombre invisible que canta con todos los hombres. 
Podríamos formalizar una recurrencia a las odas como experiencia del vivir. En ellas canta a su percibir y a su vivir, y nacen sentidos expresivos en una 'oda a la cebolla', 'oda al día feliz', 'oda al pan', 'oda a la pobreza', 'oda a la tierra', 'oda a la vida', 'oda al vino' y muchas otras. Todas ellas, como toda su obra poética, son expresiones de ese vivir que quiere ser dicho a todos los hombres. En ellas expresa impactos emocionales del mundo en su conciencia y redescubre las cosas en una visión 'simpática' penetrándolas hasta un fondo de sentidos insospechados.

De allí que en sus Memorias manifieste ese interno vivir que siente como una realidad de su tiempo transcurrido. Su mirar es un confesar su vivencia entre los hombres como forma de hacer poesía y de descubrir un sentido a lo poético, expresado en la vivencia de su tierra, de su realidad y de las circunstancias de ese mismo vivir. En ellas se nos muestran las 'categorías' que virtualizan su percibir y sentir poético de la realidad.

Esta forma de vivenciar es la del poeta, que no relata sino entrega los 'fantasmas' de ese sentir. 'Las memorias del memorialista no son las memorias del poeta. Aquél vivió tal vez menos, pero fotografió mucho más y nos recrea con la pulcritud de los detalles. Éste nos entrega una galería de fantasmas sacudidos por el fuego y la sombra de su época" (p. 7). ${ }^{13}$

Es por ello que una de las raíces de su sentir poético, que es al mismo tiempo una forma de su poesía, está dada por su nacer y vivir, por su habitar un lugar determinado que, él mismo confiesa, ha acompañado en su lejano y casi vagabundo vivir entre los hombres: "Quien no conoce el bosque chileno no conoce este planeta. De aquellas tierras, de aquel barro, de aquel silencio, he salido yo a andar, a cantar por el mundo" (p. 10). "En esta frontera, o Far West de mi patria, nací a la vida, a la tierra, a la poesía y a la lluvia" (p. 11). "La naturaleza me daba allí una especie de embriaguez. Me atraían los pájaros, los esca-

${ }^{13}$ Pablo Neruda, Confieso que he vivido, 1994, Madrid, RBA. Todas las citas de la obra pertenecen a esta edición. 
CIRO E. SCHMIDT

rabajos, los huevos de perdiz... Era milagroso encontrarlos en las... quebradas, empavonados, oscuros y relucientes, con un color parecido al del cañón de una escopeta. Me asombraba la perfección de los insectos" (p. 13).

Es allí donde descubre la poesía de la naturaleza, en una zona repleta de bosques y de lluvia, en la que se le aparece 'el arte de la lluvia': "Así como se desataban el frío, la lluvia y el barro de las calles, es decir, el cínico y desmantelado invierno del sur de América, el verano también llegaba a esas regiones, amarillo y a abrasador. Estábamos rodeados de montañas vírgenes, pero yo quería conocer el mar" (p. 19). Y pudo conocerlo: "No sólo eran las inmensas olas nevadas que se levantaban a muchos metros sobre nuestras cabezas, sino un estruendo de corazón colosal, la palpitación del universo" (p. 22).

$\mathrm{Su}$ poesía nace de su tierra y de su forma de vivir en ella, en su naturaleza y en sus habitantes, haciendo de ese habitar un sentir expresivo de la interioridad de su propio yo, y se empapa de vida como se empapa de lluvia:

Apenas se distinguen como gotas de sangre los copihues. Soy sólo un ser minúsculo bajo los helechos gigantes. Junto a mi boca vuela una torcaza con un ruido seco de alas. Más arriba otros pájaros se ríen de mí con risa ronca.

Se descarga la lluvia corno una catarata. En un minuto la noche y la lluvia cubren el mundo. Allí estoy solo y en mi cuaderno de aritmética escribo versos.

Qué soledad la de un pequeño niño poeta, vestido de negro, en la frontera espaciosa y terrible (p. 26).

Es por ello que insiste y reitera su vivencia geográfica que lo hace ser poeta de una forma particular, en la que refleja su habitar la tierra desde su tierra: "Hasta ahora sigo siendo un poeta de la intemperie, de la selva fría que perdí desde entonces...", aun cuando en la ciudad también viva desde ese mirar: "me sentaba yo a mirar la agonía de 
cada tarde, el cielo embanderado de verde y carmín, la desolación de los techos suburbanos amenazados por el incendio del cielo".

Por el lado de los bosques me saludan los avellanos de ramajes verdeoscuros y brillantes, tachonados a veces por racimos de frutas, avellanas que parecían pintadas de bermellón, tan rojas son en esa época del año. Los colosales helechos del sur de Chile eran tan altos que pasábamos bajo sus ramas sin tocarlos, yo y mi caballo. Cuando mi cabeza rozaba sus verdes, caía sobre nosotros una descarga de rocío (p. 29).

Cerca de mí todo lo que existió y siguió existiendo para siempre en mi poesía: el ruido lejano del mar, el grito de los pájaros salvajes, y el amor ardiendo sin consumirse como una zarza inmortal (p. 63).

Yo crecí es esta ciudad, mi poesía nació entre el cerro y el río, tomó la voz de la lluvia, se impregnó de los bosques tal como la madera (p. 215).

Las tierras de la frontera metieron sus raíces en mi poesía y nunca han podido salir de ella. Mi vida es una larga peregrinación que siempre da vueltas, que siempre retorna al bosque austral, a la selva perdida (p. 231).

Nada más hermoso que esas grandes manos abiertas, heridas y quemadas, que atravesándose en un sendero del bosque nos dicen el secreto del árbol enterrado, el enigma que sustentaba el follaje, los músculos profundos de la dominación vegetal. Trágicas o hirsutas, nos muestran una nueva belleza: son esculturas de la profundidad; obras maestras y secretas de la naturaleza (p. 232).

aquella poesía acompañada de la lluvia estaba ya en mis libros, tenía que ver conmigo (p. 234).

Esta realidad marca su decir poético y su forma de mirar el mundo, dándole, por lo menos en sus inicios, una tonalidad casi melancólica, 
que vieron aquellos con los que compartió sus primeros poemas: "el público tosía... y se divertía mucho con mi melancólica poesía” (p. 38).

Y este mirar lo traslada también a otras realidades geograficas que visualiza desde la de su origen. Es por ello que, al hablar del norte de Chile, dice: "Yo procedo del otro extremo de la república. Nací en tierras verdes, de grandes arboledas selváticas. Tuve una infancia de lluvia y nieve. El hecho solo de enfrentarme a aquel desierto lunar significaba un vuelco en mi existencia" (p. 204). Pero es este mismo mirar desde lo verde y lo lluvioso el que le permite descubrir la poesía del color y de los tonos, que nos muestra en una hermosa página en la que describe la primavera de la zona costera, en la que instala uno de sus últimos habitares.

Esta germinación pequeña y poderosa reviste laderas, rodea las rocas, se adelanta hacia el mar y surge en medio de nuestros caminos cotidianos, como si quisiera desafiarnos, probarnos su existencia. Tanto tiempo sostuvieron esas flores una vida invisible, tanto tiempo las apabulló la desolada negación de la tierra estéril, que ahora todo les parece poco para su fecundidad 132 amarilla.

Luego se extinguen las pequeñas flores pálidas y todo se cubre de una intensa floración violeta. El corazón de la primavera pasó del amarillo al azul, y luego al rojo. ¿Cómo se sustituyeron unas a otras las pequeñas, desconocidas, infinitas corolas? El viento sacudía un color y al día siguiente otro color, como si entre las solitarias colinas cambiara el pabellón de la primavera y las repúblicas diferentes ostentaran sus estandartes invasores. En esta época florecen los cactus de la costa. Lejos de esta región, en los contrafuertes de la cordillera andina, los cactus se elevan gigantescos, estriados y espinosos, como columnas hostiles. Los cactus de la costa, en cambio, son pequeños y redondos. Los vi coronarse con veinte botones escarlatas, como si una mano hubiera dejado allí su a ardiente tributo de gotas de sangre. Después se abrieron. Frente a las grandes espumas blan- 
cas del océano se divisan miles de cactus encendidos por sus flores plenarias (p. 357).

Así, la realidad de su geografía, vivida como sustento afirmativo de su sentir es una de las categorías de base que fundamentan su expresión poética y que la hacen nacer. Sin embargo ella se une a personas y en ella se muestra el amor, como presencia que sustenta su relación con los que viven más cerca: "Muchas veces me han preguntado cuándo escribí mi primer poema, cuándo nació en mí la poesía. Trataré de recordarlo. Muy atrás en mi infancia y habiendo apenas aprendido a escribir, sentí una vez una intensa emoción y tracé unas palabras semirrimadas, pero entrañas a mí, diferentes del lenguaje diario. Las puse en limpio en un papel, preso de una ansiedad profunda, de un sentimiento hasta entonces desconocido, especie de angustia y tristeza. Era un poema dedicado a mi madre..." (p. 27).

Esta realidad geográfica, que lo acompañará siempre, es la que da el tono sombrío de su primera poesía, adolescente: "Mi lluviosa torpeza, mi ensimismamiento prolongado duró más de lo necesario..." "surgía una pálida curiosidad por este nuevo poeta de poco más de 16 años" (p. 43) y del que busca desprenderse un poco más tarde: "despojarme de mi tono sombrío" (p. 48).

Su poesía es amante de la tierra, pero con un amor que se nos muestra muy íntimo: "Aunque mi poesía no es 'olorosa ni aérea' sino tristemente terrenal, me parece que esos temas, tan repetidamente enlutados, tienen que ver con la intimidad retórica de aquella música que convivió conmigo" (p. 121) y que lo hace sentir siempre la presencia de la realidad nativa de su vivir: "Yo no puedo vivir sino en mi propia tierra; no puedo vivir sin poner los pies, las manos y los oídos en ella, sin sentir la circulación de sus aguas y de sus sombras, sin sentir cómo mis raíces buscan en su légamo las substancias maternas" (p. 202).

Había casi terminado el primer volumen de Residencica en la tierra. Sin embargo, mi trabajo había adelantado con lentitud. Estaba separado del mundo mío por la distancia y por el silen- 
CIRO E. SCHMIDT

cio, y era incapaz de entrar de verdad en el extraño mundo que me rodeaba.

Mi libro recogía como episodios naturales los resultados de mi vida suspendida en el vacío: "Más cerca de la sangre que de la tinta." Pero mi estilo se hizo más acendrado y me di alas en la repetición de una melancolía frenética. Insistí por verdad y por retórica (porque esas harinas hacen el pan de la poesía) en un estilo amargo que porfió sistemáticamente en mi propia destrucción. El estilo no es sólo el hombre. Es también lo que lo rodea, y si la atmósfera no entra dentro del poema, el poema está muerto: muerto porque no ha podido respirar (p. 119). En estos días me ha traído mi hermana un cuaderno que contiene mis más antiguas poesías, escritas en 1918 y 1919. Al leerlas he sonreído ante el dolor infantil y adolescente, ante un sentimiento literario de soledad que se desprende de toda mi obra de juventud. El escritor joven no puede escribir sin ese estremecimiento de soledad, aunque sea ficticio, así como el escritor maduro no hará nada sin el sabor de compañía humana, de sociedad (p. 113).

Por ello hace profesión de realismo, pero entendido como síntesis entre la percepción objetiva de la realidad, la vivencia subjetiva, y por lo mismo amante de la misma, y la racionalidad que es camino de comunicación con los otros. Ser poeta es vivir entre los hombres y no en un mundo ajeno a una realidad que comparte con ellos: "El poeta que no sea realista va muerto. Pero el poeta que sea sólo realista va muerto también. El poeta que sea sólo irracional será entendido sólo por su persona y por su amada, y esto es bastante triste. El poeta que sea sólo un racionalista, será entendido hasta por los asnos, y esto es también sumamente triste" (p. 316).

La cercanía y la 'visión simpática' con esta realidad es la que busca expresar en las Odas, al mostrar lo poético de la misma en una íntima comunión con lo cotidiano. 
En las Odas elementales me propuse un basamento original, nacedor. Quise redescubrir muchas cosas ya cantadas, dichas y redichas. Mi punto de partida deliberado debía ser el del niño que emprende, chupándose el lápiz, una composición obligatoria sobre el sol, el pizarrón, el reloj o la familia humana. Ningún tema podía quedar fuera de mi órbita; todo debía tocarlo yo andando o volando, sometiendo mi expresión a la máxima transparencia y virginidad.

...Quieren obligar a los creadores a no tratar sino temas sublimes. Pero se equivocan. Haremos poesía hasta con las cosas más despreciadas por los maestros del buen gusto (p. 351).

Desde esa inserción en la realidad del vivir se acerca a la presencia del amor como forma relacionante de lo humano. Por ello su sentir amoroso tiene la forma amplia de todo lo verdaderamente humano y, si es cierto que se acerca a la pasión adolescente en sus poemas de amor, no es menos cierto que se abre a toda la presencia del hombre en la amplitud de su comunión con lo humano.

Los Veinte poemas de amor y una canción desesperada son un libro doloroso y pastoril que contiene mis más atormentadas pasiones adolescentes, mezcladas con la naturaleza arrolladora del sur de mi patria (p. 63).

Distinguimos en el silencio las cuerdas de una guitarra y las palabras de una canción que, naciendo de las brasas y de la oscuridad, nos traía la primera voz humana que habíamos topado en el camino. Era una canción de amor y de distancia, un lamento de amor y de nostalgia dirigido a la primavera, hacia las ciudades lejanas de donde veníamos, hacia la infinita extensión de la vida (p. 223).

Por ello siente que la poesía, abierta a todo amor, tiene una cierta cercanía con la locura. A los poetas les cuesta ser razonables en tanto viven la intensidad de su simpatía con las cosas, pero por sobre todo con 
CIRO E. SCHMIDT

la humanidad de todos y de cada uno: "diré que la locura, cierta locura, anda muchas veces del brazo con la poesía. Así como a las personas más razonables les costaría mucho ser poetas, quizás a los poetas les cuesta mucho ser razonables" (p. 51). "De todas maneras me parece que yo no nací para condenar sino para amar" (p. 56).

Desde allí se abre a la realidad de todo lo humano en la limpia sencillez de su vivir: "La ropa a secar embandera cada casa y la incesante proliferación de pies descalzos delata con su colmena el inextinguible amor" (p. 70). "Sin embargo no hay pocos zapatos en mi poesía. Ellos circulan taconeando en muchas de mis estrofas, sin que yo me haya propuesto ser un poeta zapateril" (p. 212).

Pero no significa que no considere todas las otras realidades del hombre, como la lucha por su vivir, su dolor y su alegría, su compromiso con los otros. Ello lo lleva a una opción política como parte de su vivir poético, la que, más allá de consideraciones directas, nos muestra otra categoría desde la que debe entenderse su quehacer poético. El poeta no vive ajeno a la realidad de los hombres con los que vive y de los cuales forma parte, con todo su bagaje de humanidad. Su condición de privilegio lo fuerza a intentar una forma de camino que, aun

136 cuando podamos no compartir desde el punto de vista de las opciones inmediatas, señala su apertura, ya cantada en la oda citada al comienzo, a la amplitud de todo lo humano, que es lo que quiere cantar.

Los poetas de esta época hemos tenido que elegir. La elección no ha sido un lecho de rosas (p. 380).

Todas las alternativas, desde el llanto hasta los besos, desde la soledad hasta el pueblo, perviven en mi poesía, actúan en ella, porque he vivido para mi poesía, y mi poesía ha sustentado mis luchas. $Y$ si muchos premios he alcanzado, premios fugaces como mariposas de polen fugitivo, he alcanzado un premio mayor, un premio que muchos desdeñan pero que es en realidad para muchos inalcanzable. He llegado a través de una dura lección de estética y de búsqueda, a través de los laberintos de la palabra escrita, a ser poeta de mi pueblo. Mi premio 
es ése, no los libros y los poemas traducidos o los libros escritos para describir o disecar mis palabras (p. 208).

El poeta debe torturarse y sufrir, debe vivir desesperado, debe seguir escribiendo la canción desesperada. Ésta es la opinión de una capa social, de una clase...

Las cosas cambiaron porque el mundo cambió. Y los poetas, de pronto, encabezamos la rebelión de la alegría.

Los poetas tenemos el derecho a ser felices, sobre la base de que estamos férreamente unidos a nuestros pueblos y a la lucha por su felicidad (p. 314).

La poesía de Neruda no puede entenderse sin enfrentarse con ella y considerar su compromiso vital con la realidad humana en toda su complejidad, incluyendo en ella la social, económica y política. En este sentido es una poética de compromiso, pero más que con una realidad política, lo que para algunos ha sido discutible, con la realidad de lo humano, en la complejidad de su vivir en el mundo de hoy, especialmente entre aquellos que viven la cercanía de la pobreza.

El poeta no puede temer al pueblo. Me pareció que la vida me hacía una advertencia y me enseñaba para siempre una lección: la lección del honor escondido, de la fraternidad que no conocemos, de la belleza que florece en la oscuridad (p. 100).

Al poeta debemos exigirle sitio en la calle y en el combate, así como en la luz y en la sombra.

Tal vez los deberes del poeta fueron los mismos en la historia. El honor de la poesía fue salir a la calle, fue tomar parte en éste y en el otro combate. No se asustó el poeta cuando le dijeron insurgente. La poesía es insurrección. No se ofendió el poeta cuando lo llamaron subversivo. La vida sobrepasa las estructuras y hay nuevos códigos para el alma. De todas partes salta la semilla; todas las ideas son exóticas; esperamos cada día cambios inmensos; vivimos con entusiasmo la mutación del orden humano; la primavera es insurreccional (p. 350). 
CIRO E. SCHMIDT

Esta utilidad pública de la poesía se basa en la fuerza, en la ternura, en la alegría y en la esencia verdadera. Sin esta calidad la poesía suena pero no canta. Alberti canta siempre (p. 168).

Parte de este vivir lo lleva a hacer también una forma de poesía que lo exprese, cumpliendo con su manifiesto de cantar a toda su vivencia de lo humano. Por ello busca expresar su sentir político en toda situación humana y con gran fuerza, especialmente, en su vivencia de la experiencia española.

Desde aquellas épocas y con intermitencia, se mezcló la política en mi poesía y en mi vida. No era posible cerrar la puerta a la calle dentro de mis poemas, así como no era posible tampoco cerrar las puertas al amor, a la vida, a la alegría o a la tristeza en mi corazón de joven poeta (p. 64).

Como en la crisis del nacimiento como en el comienzo alarmante y alarmado del terror metafísico de donde brota el manantial de mis primeros versos, como en un nuevo crepúsculo que mi propia creación ha provocado, entro en una agonía y en la segunda soledad...

A las primeras balas que atravesaron las guitarras del España, cuando en vez de sonidos salieron de ellas borbotones de sangre mi poesía se detiene como un fantasma en medio de las calles de la angustia humana y comienza a subir por ella una corriente de raíces y de sangre. Desde entonces mi camino se junta con el camino de todos. $Y$ de pronto veo que desde el sur de la soledad he ido hacia el norte que es el pueblo, el pueblo al cual mi humilde poesía quisiera servir de espada y de pañuelo, para secar el sudor de sus grandes dolores y para darle un arma en la lucha del pan.

Entonces el espacio se hace grande, profundo y permanente. Estamos ya de pie sobre la tierra. Queremos entrar en la posesión infinita de cuanto existe. No buscamos el misterio, somos el misterio. Mi poesía comienza a ser parte material de un 
ambiente infinitamente espacial, de un ambiente a la vez submarino y subterráneo, a entrar por galerías de vegetación extraordinaria, a conversar a pleno día con fantasmas solares, a explorar a la vacidad del mineral escondido en la tierra...

Un nuevo continente se levanta de la más secreta materia de mi poesía (p. 183).

Así, al abrirse a toda la realidad de lo humano, su expresión poética busca ser fuente de comunicación. Ella es intento de unión entre los hombres, circulando entre todos ellos y buscando ser expresión de sus anhelos, sus dolores y sus alegrías. El poeta "cuya alma tiene menos fronteras que las de los demás" (p. 386 en referencia a las relaciones de Chile con Perú) es puente que posibilita restañar el pasado, al mismo tiempo que unir en el presente y en anhelos comunes.

mi poesía abrió el camino de comunicación y pude andar y circular y ser recibido como un hermano imperecedero, por mis compatriotas de vida dura (p. 203 al referirse a su experiencia en Machu Picchu).

Por ello canta al hombre americano y ama profundamente su raíz hispana en la profundidad de su sentir por España, por México, por Perú, como lo muestra por ejemplo en su Canto general.

Sin embargo esta cercanía va más allá de una expresión que puede parecer retórica, y se refleja en su experiencia de poeta que canta a los hombres en medio de ellos. En sus Memorias relata, más de una vez, su sentir al cantar sus versos y la impresión que éstos provocaron.

Al leer poema tras poema, al sentir el silencio como de agua profunda en que caían mis palabras, al ver cómo aquellos ojos y cejas oscuras seguían intensamente mi poesía, comprendí que mi libro estaba llegando a su destino. Seguí leyendo y leyendo, conmovido yo mismo por el sonido de mi poesía, 
CIRO E. SCHMIDT

sacudido por la magnética relación entre mis versos y aquellas almas abandonadas (p. 303).

Yo me lancé a la vida más desnudo que Adán, pero dispuesto a mantener la integridad de mi poesía.

...se rindieron como buenos seres humanos ante lo esencial que mis versos despertaban (p. 316).

Por ello es necesario que la poesía permanezca viva en el contacto con los hombres, viva en el contacto con aquel que la escucha o con aquel que la lee. Lejana a lo humano pierde su capacidad de comunión y sólo pasa a ser un ejercicio de palabras, pero carece de sentido. Todo lo humano debe estar presente en ella, como señalaba en la 'Oda al hombre invisible', pues ello es el tema de todo su canto.

La poesía ha perdido su vínculo con el lejano lector... Tiene que recobrarlo... Tiene que caminar en la oscuridad y encontrarse con el corazón del hombre, con los ojos de la mujer, con los desconocidos de las calles, de los que a cierta hora crepuscular, o en plena noche estrellada, necesitan aunque sea no más que un solo verso... Esa visita a lo imprevisto vale todo lo andado, todo lo leído, todo lo aprendido... Hay que perderse entre los que no conocemos para que de pronto recojan lo nuestro de la calle, de la arena, de las hojas caídas mil años en el mismo bosque... y tomen tiernamente ese objeto que hicimos nosotros... Sólo entonces seremos verdaderamente poetas... En ese objeto vivirá la poesía... (p. 311).

El hombre es, en su vivir, en su naturaleza, esencialmente poético, y, como tal, abierto a toda poesía que lo exprese y ésta, a su vez, tiene que tenerlo como tema ejemplar de su decir. Su canto a la naturaleza y a toda otra forma de realidad lo es porque son realidades cercanas a lo humano y miradas con ojos humanos. La poesía es expresión del hombre todo. 
La inclinación profunda del hombre es la poesía y de ella salió la liturgia, los salmos, y también el contenido de las religiones. El poeta se atrevió con los fenómenos de la naturaleza y en las primeras edades se tituló sacerdote para preservar su vocación. De ahí que, en la época moderna, el poeta, para defender su poesía, tome la investidura que le dan la calle y las masas (p. 317).

el poeta puede escribir sobre lo que se le indique, sobre aquello que sea necesario para la colectividad humana.

Un poeta puede escribir sobre una universidad o un sindicato, para los gremios y los oficios. Nunca se perdió la libertad para eso. La inspiración mágica y la comunicación con Dios son invenciones interesadas (p. 319).

Sin embargo hay inspiración y creación expresada en palabras, más allá de los puros sentimientos. La palabra es el medio de comunicación propio del poeta. Alli se patentiza el decir heideggeriano, al aparecer ella como la 'casa del ser'

Después de cuarenta años de experiencia creo que la obra poética puede llegar a un dominio más sustancial de las emociones. Se necesitan para ello reservas de observaciones, de palabras,... hay que de cazarlas de inmediato (p. 319).

...Todo lo que usted quiera, sí señor, pero son las palabras las que cantan, las que suben y bajan... Me prosterno ante ellas... Las amo, las adhiero, las persigo, las muerdo, las derrito. Amo tanto las palabras... Las inesperadas... Las que glotonamente se esperan, se acechan, hasta que de pronto caen... Vocablos amados...

Todo está en la palabra... Una idea entera se cambia porque una palabra se trasladó de sitio, o porque otra se sentó como una reinita adentro de una frase que no la esperaba y que la obedeció... Tienen sombra, transparencia, peso, plumas... (p. 65). 
CIRO E. SCHMIDT

Sin embargo, y por lo mismo, la tarea del escritor, y en ella la tarea del poeta, implica esfuerzo 'tiernamente logrado' como todo objeto creado con el trabajo humano

Yo siempre he sostenido que la tarea del escritor no es misteriosa ni trágica, sino que, por lo menos la del poeta, es una tarea personal, de beneficio público. Lo más parecido a la poesía es un pan o un plato de cerámica, o una madera tiernamente labra$\mathrm{da}$, aunque sea por torpes manos. Sin embargo, creo que ningún artesano puede tener, como el poeta la tiene, por una sola vez durante su vida, esta embriagadora sensación del primer objeto creado con sus manos, con la desorientación aún palpitante de sus sueños (p. 60).

Es cierto que la poesía puede ser fruto de inspiración, pero en su esfuerzo personal y en su contacto con otros poetas, contacto que ocupa grandes espacios de esta obra, nos muestra cómo la poesía es también trabajo arduo por senderos pequeños. Así hablando de Sabat Ercasty, poeta uruguayo dice que "en ese poeta había visto yo realizada mi

142 ambición de una poesía que englobara no sólo al hombre sino a la naturaleza, a las fuerzas escondidas; una poesía epopéyica que se enfrentara con el gran misterio del universo y también con las posibilidades del hombre... con él terminó también mi ambición cíclica de una ancha poesía" (p. 62), "estaba equivocado, debía desconfiar de la inspiración. La razón debía guiarme paso a paso por los pequeños senderos" (p. 62).

Por ello su búsqueda poética se muestra también en el contacto con otros poetas: "Por esos días conocí a César Vallejos, el gran cholo; poeta de poesía arrugada, difícil al tacto como piel selvática, pero poesía grandiosa, de dimensiones sobrehumanas" (p. 82), así como en el contacto con otros pueblos y con otras realidades, y que es trabajado y asimilado en la lentitud del tiempo: “...la guerra de España, que cambió mi poesía, comenzó para mí con la desaparición de un poeta" (p. 147: se refiere a Federico García Lorca por quien tuvo un profundo aprecio 
y admiración). Muchos recuerdos de esta poesía compartida en su vivencia de entonces, viven todavía en su memoria.

El recuerdo de Miguel Martínez no puede escapárseme de las raíces del corazón. El canto de los ruiseñores levantinos, sus torres de sonidos erigidas entre la oscuridad y los azahares, eran para él presencia obsesiva, y eran parte del material de su sangre, de su poesía terrenal y silvestre en la que se juntaban todos los excesos del color, del perfume y de la voz del Levante español, con la abundancia y la fragancia de poderosa y masculina juventud.

Su rostro era el rostro de España. Cortado por la luz, arrugado como una sementera, con algo de rotundo de pan y de tierra. Sus ojos quemantes, ardiendo dentro de esa superficie quemada y endurecida al viento, eran dos rayos de fuerza y de ternura. Los elementos mismos de la poesía los vi salir de sus palabras, pero alterados ahora por una nueva magnitud, por un resplandor salvaje, por el milagro de la sangre vieja transformada en un hijo. En mis años de poeta, y de poeta errante, puedo afirmar que la vida no me ha dado contemplar un fenómeno igual de vocación y de ecléctica sabiduría verbal (p. 143).

Al mismo tiempo su viajar por el mundo también lo abre a una visión poética universal, plasmada en el sentir inmediato de su tierra, aun cuando muchos de sus diversos estares no se reflejen con facilidad en su obra. Hablando de su estadía en Oriente señala: "No creo, pues, que mi poesía de entonces haya reflejado otra cosa que la soledad de un forastero transplantado a un mundo violento y extraño" (p. 104). Es en la lejanía de su tierra donde vive sus momentos poéticos más dolorosos: "Luego vendrían otros tres meses de inacción, de contemplación ermitaña de mercados y templos. Ésta es la época más dolorosa de mi poesía" (p. 106).

Todo lo anterior nos muestra cómo en Neruda vivir y poetizar son una sola realidad en la que ambas se penetran mutuamente a lo largo 
CIRO E. SCHMIDT

de toda su vida, de tal manera que no es posible separarlas, pues se iluminan mutuamente. La poesía es para él un flujo continuo de vivencias, si pierde esta fuerza dinámica pierde todo su sentido como poesía.

La poesía no es una materia estática, sino una corriente fluida que muchas veces se escapa de las manos del propio creador. Su materia prima está hecha de elementos que son y al mismo tiempo no son, de cosas existentes e inexistentes. De todos modos, trataré de responderle con sinceridad. Para mí el color azul es el más bello de los colores. Tiene la implicación del espacio humano, como la bóveda celeste, hacia la libertad y la alegría. La presencia de Federico, su magia personal, imponían una atmósfera de júbilo a su alrededor. Mi verso probablemente quiere decir que incluso los hospitales, incluso la tristeza de los hospitales, podían transformarse bajo el hechizo de su influencia y verse convertidos de pronto en bellos edificios azules (p. 149).

Por lo mismo el poetizar es una mezcla de trabajo y contemplación, 144 de gozo tranquilo en el ocio y esfuerzo conquistador de la palabra, trabajada en la búsqueda de su sentido más profundo: "Disfruté el placer poético de perder muchas veces el tiempo... Si los poetas contestaran de verdad a las encuestas largarían el secreto: no hay nada tan hermoso como perder el tiempo" (p. 152). "El oficio de poeta es, en gran parte, pajarear" (p. 299). "Yo sigo trabajando con los materiales que tengo y que soy. Soy omnívoro de sentimientos, de seres, de libros, de acontecimientos y batallas. Me comería toda la tierra. Me bebería todo el mar" (p. 315).

Buscando, como hombre y como poeta, mirar las cosas y los hombres, intentó una poesía no ajena a la realidad de lo humano, estableciendo una forma de visión sintética entre lo real objetivo y su propio mirar esa realidad: "Como poeta combatí mi propio ensimismamiento. Por eso el debate entre lo real y lo subjetivo se decidió dentro de mi propio ser" (p. 315). 
En ese mirar no hay expresión teórica sino libertad interior, y por ello tampoco hay ninguna forma de compromiso con tendencia alguna sino vivencia con la poesía de su tiempo, en todas sus formas, en aquellos que la expresaron junto a él.

Para buscar lo indefinible, la guía o el hilo que une el hombre a la obra, hablo de aquellos que tuvieron algo o mucho que ver conmigo. Vivimos en parte la vida juntos y ahora yo los sobrevivo. No tengo otro medio de indagar lo que se ha dado en llamar el misterio poético y que yo llamaría la claridad poética. Tiene que haber alguna relación entre las manos y la obra, entre los ojos, las vísceras, la sangre del hombre y su trabajo. Pero yo no tengo teoría. No ando con un dogma debajo del brazo para dejárselo caer en la cabeza de nadie (p. 338).

En cuanto al realismo debo decir, porque no me conviene hacerlo, que detesto el realismo cuando se trata de la poesía. Es más, la poesía no tiene por qué ser sobrerrealista o subrealista. Esto último con toda la razón, con toda la sinrazón, es decir, con toda la poesía.

Me place el libro, la densa materia del trabajo poético, el bosque de la literatura, me place todo, hasta los lomos de los libros, pero no las etiquetas de las escuelas. Quiero libros sin escuelas y sin clasificar, como la vida (p. 349).

Me enteré mucho después de estar haciéndolo, que lo que yo escribía se llamaba poesía. Nunca he tenido interés en las definiciones, en las etiquetas. Me aburren a muerte las discusiones estéticas. No disminuyo a quienes las sustentan, sino que me siento ajeno tanto a la partida de nacimiento como al post mortem de la creación literaria (p. 399).

Así, en definitiva, la forma de sentir de lo poético es la de un profundo compromiso con la realidad de lo humano y de sus circunstancias, expresado en la belleza de la palabra, en la que queda, como un balbuceo, un más allá al que no pudo abrirse. 
CIRO E. SCHMIDT

Pienso, por ello, que su credo poético, que no es una teoría estética, se puede resumir con sus propias palabras:

Soy parte de la esencial o mayoría, soy una hoja más del gran árbol humano.

Soledad y multitud seguirán siendo deberes elementales del poeta de nuestro tiempo (p. 399). 